\title{
Research of total phosphorus concentration in Hefei Ring River based on landsat-8 satellite image data
}

\author{
Kun Ding ${ }^{1,2,3 *}$, Chen Yang ${ }^{1,2,3}$, Chuan-hua Zhu ${ }^{1,2}$, Yong Zhang ${ }^{1,2}$, Hui Zhang ${ }^{1,2}$, Yi Zhang ${ }^{1,3}$ and Yang $\mathrm{Xu}^{1,3}$ \\ ${ }^{1}$ College of Environmental and Energy Engineering, Anhui Jianzhu University, 230000 Hefei Anhui, China \\ ${ }^{2}$ Key Laboratory of Anhui Province of Water Pollution Control and Wastewater Reuse, Anhui Jianzhu University, 230000 Hefei Anhui, \\ China \\ ${ }^{3}$ Key Laboratory of Huizhou Architecture in Anhui Province, Anhui Jianzhu University, 230000 Hefei Anhui, China
}

\begin{abstract}
Total phosphorus (TP) in water is an important indicator reflecting water environment and water ecology. If the concentration exceeds the standard, it will directly lead to eutrophication. The daily monitoring of total phosphorus in water bodies has already mentioned the important agenda of environmental protection, while the routine testing has a large workload and heavy tasks. We used satellite remote sensing technology to extract image data and establish a mathematical models, what was used to invert the total phosphorus concentration in water. Taking the Ring River as an example, we selected different time nodes to sample and measure the TP value, and use the landsat- 8 image data to establish a semi-empirical regression model. The model structure, the calculation results found that the error with the measured data is within the controllable range. The method is simple in operation, saves resources, manpower and financial resources, and can accurately reflect the actual situation of the water body TP.
\end{abstract}

\section{Introduction}

In recent years, with the rapid development of China's economy, urbanization construction is getting faster and faster. In order to improve urban greening and enhance the urban living environment, urban closed waters are gradually increasing. Compared with large lakes, urban closed water bodies are more susceptible to external disturbances and water quality is more susceptible to pollution ${ }^{[1-2]}$. At present, the eutrophication of closed water bodies in many cities is becoming more and more serious. The stench of water bodies and the frequent occurrence of cyanobacteria seriously affect the urban water ecological environment and the quality of life of residents. How to protect and improve water quality has become a focus of today's environmental protection.

The evaluation indexes of water quality mainly include ammonia nitrogen $\left(\mathrm{NH}_{3}-\mathrm{N}\right)$, chemical oxygen demand (COD), total phosphorus (TP), total nitrogen (TN), suspended solid particles (SS), etc. ${ }^{[3]}$, most of the current monitoring methods are taken from the field and taken back to the laboratory for analysis, but the water sample should be analyzed within 24 hours. Although transportation is now very developed, it is inevitably affected by the weather and other factors, resulting in the inability to accurately and accurately measure water samples in a short period of time. Remote sensing has the characteristics of wide coverage and rich information, which is conducive to the observation of the continuous variation and spatial distribution of water quality ${ }^{[4]}$. In the existing remote sensing technology monitoring water quality, with the continuous development of remote sensing technology and the improved resolution accuracy of remote sensing images, more and more variables can be used to monitor water quality. Among these water quality variables, many models are more mature. There are three types of chlorophyll, suspended matter, and yellow matter ${ }^{[5]}$. This study used landsat- 8 image data to use the data of March 16, 2019 and April 27, 2019 to establish a model for detecting total phosphorus concentration in the waters of the Ring River, and applied it to landsat-8 from May to June 2019. In the image, the temporal and spatial variation of the total phosphorus concentration in the waters of the Ring River is estimated, and the water quality of the Ring River is evaluated. The aim is to provide a scientific basis for monitoring the eutrophication of the Ring River and water pollution control.

\section{Overview of the study area}

The predecessor of the Ring City River is the ancient moat, which is composed of the Nanfei River through the part of Hefei City. Due to the urban planning and development, this jade necklace-like moat is scattered into a lake and a pond. For a long time, the recharge water source of the Ring River is the reclaimed water reuse and natural precipitation of the urban sewage reclaiming project. When the dry season is over, the Dongpu Reservoir, which is protected by drinking water sources, will be replenished. In general, the water body

\footnotetext{
*Corresponding author: 874408959@qq.com
} 
of the Ring River is closed ${ }^{[6]}$. According to the survey conducted by the Municipal Environmental Protection Bureau in recent years, the overall water quality of the Ring River water body is inferior to the $\mathrm{V}$ category all the year round, and the water environment is not optimistic.

\section{Materials and methods}

\subsection{Collection of water quality data}

In order to fully reflect the water quality of the Ring River, the layout of sampling points should follow the basic principles of comprehensive coverage, uniform distribution and strong representativeness. Figure 1 shows the location of specific sampling points in the water body of the Ring River. A total of 10 sampling points were laid. On March 16, 2019 and April 27, 2019, water samples were collected in the Ring River. The water sample was brought back to the laboratory to complete the TP measurement within $24 \mathrm{H}$. The data of March 16, 2019 was used for model. The data of April 27, 2019 was used to verify the model.

Table 1. Specific location of the sampling point of the ring River

\begin{tabular}{|c|c|c|}
\hline $\begin{array}{c}\text { Sample point } \\
\text { number }\end{array}$ & $\begin{array}{l}\text { Latitude and } \\
\text { longitude }\end{array}$ & address \\
\hline $\mathrm{H} 1$ & $\begin{array}{l}31^{\circ} 51^{\prime} 20^{\prime \prime} \mathrm{N} \\
117^{\circ} 16^{\prime} 03^{\prime \prime} \mathrm{E}\end{array}$ & Yuhuatang 1 \\
\hline $\mathrm{H} 2$ & $\begin{array}{l}31^{\circ} 51^{\prime} 19^{\prime \prime} \mathrm{N} \\
117^{\circ} 16^{\prime} 22^{\prime \prime} \mathrm{E}\end{array}$ & Yuhuatang 2 \\
\hline $\mathrm{H} 3$ & $\begin{array}{l}31^{\circ} 51^{\prime} 23^{\prime \prime} \mathrm{N} \\
117^{\circ} 16^{\prime} 44^{\prime \prime} \mathrm{E}\end{array}$ & Galaxy Park \\
\hline $\mathrm{H} 4$ & $\begin{array}{l}31^{\circ} 51^{\prime} 27^{\prime \prime} \mathrm{N} \\
117^{\circ} 16^{\prime} 54^{\prime \prime} \mathrm{E}\end{array}$ & Baohe Park 1 \\
\hline H5 & $\begin{array}{l}31^{\circ} 51^{\prime} 31^{\prime \prime} \mathrm{N} \\
117^{\circ} 17^{\prime} 09^{\prime \prime} \mathrm{E}\end{array}$ & Baohe Park 2 \\
\hline H6 & $\begin{array}{l}31^{\circ} 51^{\prime} 38^{\prime \prime} \mathrm{N} \\
117^{\circ} 17^{\prime} 27^{\prime \prime} \mathrm{E}\end{array}$ & Time gate bridge \\
\hline $\mathrm{H} 7$ & $\begin{array}{l}31^{\circ} 51^{\prime} 56^{\prime \prime} \mathrm{N} \\
117^{\circ} 17^{\prime} 39^{\prime \prime} \mathrm{E}\end{array}$ & Xiaoyaojin Park \\
\hline H8 & $\begin{array}{l}31^{\circ} 52^{\prime} 16^{\prime \prime} \mathrm{N} \\
117^{\circ} 17^{\prime} 39^{\prime \prime} \mathrm{E}\end{array}$ & $\begin{array}{c}\text { Intersection of Suzhou Road } \\
\text { and Yanhe Road }\end{array}$ \\
\hline H9 & $\begin{array}{l}31^{\circ} 52^{\prime} 34^{\prime \prime} \mathrm{N} \\
117^{\circ} 16^{\prime} 59^{\prime \prime} \mathrm{E}\end{array}$ & $\begin{array}{c}\text { Intersection of Fuyang North } \\
\text { Road and Yanhe Road }\end{array}$ \\
\hline H10 & $\begin{array}{l}31^{\circ} 52^{\prime} 35^{\prime \prime} \mathrm{N} \\
117^{\circ} 16^{\prime} 30^{\prime \prime} \mathrm{E}\end{array}$ & $\begin{array}{l}\text { Intersection of Mengcheng } \\
\text { North Road and Yanhe Road }\end{array}$ \\
\hline
\end{tabular}


performs one-way and multiple regression analysis, selects the appropriate regression model, and finally verifies and evaluates the model.

\section{Results and discussion}

\subsection{Model establishment and testing}

\subsubsection{Model establishment}

The reflectivity of the obtained 7 bands are combined. The combination includes the sum, difference, and ratio of any two bands and the NDVI algorithm $\left(r_{i}-r_{j} / r_{i}+r_{j}\right) . i \neq j$, the $r_{i}$ and $r_{j}$ of the formula represent the reflectance of different bands ${ }^{[11]}$. Correlation analysis was performed between the single-band reflectance and the reflectance obtained by combining the bands with the measured values of TP. The reflectance factor with a correlation of TP above 0.4 reached $69.48 \%$ of the total reflectance factor. The table 2 shows all reflectance factors above0.6.

Table 2. Band combination with TP concentration correlation coefficient greater than 0.6

\begin{tabular}{|c|c|c|c|c|}
\hline $\begin{array}{l}\text { Combination } \\
\text { method }\end{array}$ & \multicolumn{4}{|l|}{$|\mathrm{R}|>0.6$} \\
\hline Single band & \multicolumn{4}{|c|}{$\begin{array}{lll}\text { B5 } & \text { B6 } & \text { B7 } \\
\end{array}$} \\
\hline $\mathrm{ri} / \mathrm{rj}$ & \multicolumn{2}{|c|}{$\begin{array}{ll}\mathrm{B} 1 / \mathrm{B} 5 & \mathrm{~B} 2 / \mathrm{B} 5 \\
\mathrm{~B} 5 / \mathrm{B} 1 & \mathrm{~B} 5 / \mathrm{B} 2 \\
\mathrm{~B} 6 / \mathrm{B} 1 & \mathrm{~B} 6 / \mathrm{B} 2 \\
\mathrm{~B} 7 / \mathrm{B} 1 & \mathrm{~B} 7 / \mathrm{B} 2 \\
\end{array}$} & \multicolumn{2}{|c|}{$\begin{array}{l}\mathrm{B} 3 / \mathrm{B} 5 \\
\mathrm{~B} 5 / \mathrm{B} 3 \\
\mathrm{~B} 6 / \mathrm{B} 3 \\
\mathrm{~B} 7 / \mathrm{B} 3\end{array}$} \\
\hline$r_{i}-r_{j} / r_{i}+r_{j}$ & \multicolumn{2}{|c|}{$\begin{array}{l}\mathrm{B} 1-\mathrm{B} 5 / \mathrm{B} 1+\mathrm{B} 5 \\
\mathrm{~B} 1-\mathrm{B} 7 / \mathrm{B} 1+\mathrm{B} 7 \\
\mathrm{~B} 2-\mathrm{B} 6 / \mathrm{B} 2+\mathrm{B} 6 \\
\mathrm{~B} 3-\mathrm{B} 5 / \mathrm{B} 3+\mathrm{B} 5 \\
\mathrm{~B} 3-\mathrm{B} 7 / \mathrm{B} 3+\mathrm{B} 7 \\
\mathrm{~B} 4-\mathrm{B} 6 / \mathrm{B} 4+\mathrm{B} 6 \\
\mathrm{~B} 5-\mathrm{B} 1 / \mathrm{B} 5+\mathrm{B} 1 \\
\mathrm{~B} 5-\mathrm{B} 3 / \mathrm{B} 5+\mathrm{B} 3 \\
\mathrm{~B} 6-\mathrm{B} 1 / \mathrm{B} 6+\mathrm{B} 1 \\
\mathrm{~B} 6-\mathrm{B} 3 / \mathrm{B} 6+\mathrm{B} 3 \\
\mathrm{~B} 7-\mathrm{B} 1 / \mathrm{B} 7+\mathrm{B} 1 \\
\mathrm{~B} 7-\mathrm{B} 3 / \mathrm{B} 7+\mathrm{B} 3\end{array}$} & \multicolumn{2}{|c|}{$\begin{array}{l}\mathrm{B} 1-\mathrm{B} 6 / \mathrm{B} 1+\mathrm{B} 6 \\
\mathrm{~B} 2-\mathrm{B} 5 / \mathrm{B} 2-\mathrm{B} 5 \\
\mathrm{~B} 2-\mathrm{B} 7 / \mathrm{B} 2+\mathrm{B} 7 \\
\mathrm{~B} 3-\mathrm{B} 6 / \mathrm{B} 3+\mathrm{B} 6 \\
\mathrm{~B} 4-\mathrm{B} 5 / \mathrm{B} 4+\mathrm{B} 5 \\
\mathrm{~B} 4-\mathrm{B} 7 / \mathrm{B} 4+\mathrm{B} 7 \\
\mathrm{~B} 5-\mathrm{B} 2 / \mathrm{B} 5+\mathrm{B} 2 \\
\mathrm{~B} 5-\mathrm{B} 4 / \mathrm{B} 5+\mathrm{B} 4 \\
\mathrm{~B} 6-\mathrm{B} 2 / \mathrm{B} 6+\mathrm{B} 2 \\
\mathrm{~B} 6-\mathrm{B} 4 / \mathrm{B} 6+\mathrm{B} 4 \\
\mathrm{~B} 7-\mathrm{B} 2 / \mathrm{B} 7+\mathrm{B} 2 \\
\mathrm{~B} 7-\mathrm{B} 4 / \mathrm{B} 7+\mathrm{B} 4\end{array}$} \\
\hline ri-rj & $\begin{array}{l}\mathrm{B} 1-\mathrm{B} 5 \\
\mathrm{~B} 2-\mathrm{B} 5 \\
\mathrm{~B} 4-\mathrm{B} 2 \\
\mathrm{~B} 5-\mathrm{B} 2 \\
\mathrm{~B} 5-\mathrm{B} 6 \\
\mathrm{~B} 7-\mathrm{B} 6\end{array}$ & $\begin{array}{l}\mathrm{B} 2-\mathrm{B} 3 \\
\mathrm{~B} 3-\mathrm{B} 2 \\
\mathrm{~B} 4-\mathrm{B} 5 \\
\mathrm{~B} 5-\mathrm{B} 3 \\
\mathrm{~B} 5-\mathrm{B} 7\end{array}$ & $\begin{array}{ll}3 & \mathrm{~B} \\
2 & \mathrm{~B} \\
5 & \mathrm{~B} \\
3 & \mathrm{~B} \\
7 & \mathrm{~B}\end{array}$ & $\begin{array}{l}-\mathrm{B} 4 \\
-\mathrm{B} 5 \\
-\mathrm{B} 1 \\
-\mathrm{B} 4 \\
-\mathrm{B} 5\end{array}$ \\
\hline ritri & $\begin{array}{l}\mathrm{B} 1+\mathrm{B} 5 \\
\mathrm{~B} 5+\mathrm{B} 6\end{array}$ & $\begin{array}{l}\mathrm{B} 2+\mathrm{B} 5 \\
\mathrm{~B} 5+\mathrm{B} 7\end{array}$ & $\begin{array}{l}\mathrm{B} 3+\mathrm{F} \\
\mathrm{B} 6+\mathrm{F}\end{array}$ & $\mathrm{B} 4+\mathrm{B} 5$ \\
\hline
\end{tabular}

Among the 154 reflection factors obtained, 107 had a correlation with TP of 0.4 or more, and 65 of them had a correlation of 0.6 or more. Among them, the correlation between B5-B2 and B2-B5 and TP was the highest. It reached 0.858962 and -0.858962 .

According to the above analysis, linear regression analysis was performed using B2-B5 with good correlation with TP concentration, and the model was applied to the remote sensing data of April 27, 2019. The correlation coefficient between predicted and measured values reached 0.9187 . The model looks like this:

$$
C_{T P}=1.912-6.64 \times(B 2-B 5)+14.135 \times(B 2-B 5)^{3}
$$

\subsubsection{Model test}

The above model (1) was applied to the Landsat-8 image selected from the sampling on April 27, 2019, and a comparative analysis of the estimated value of the TP concentration of the Ring River and the measured value was obtained.

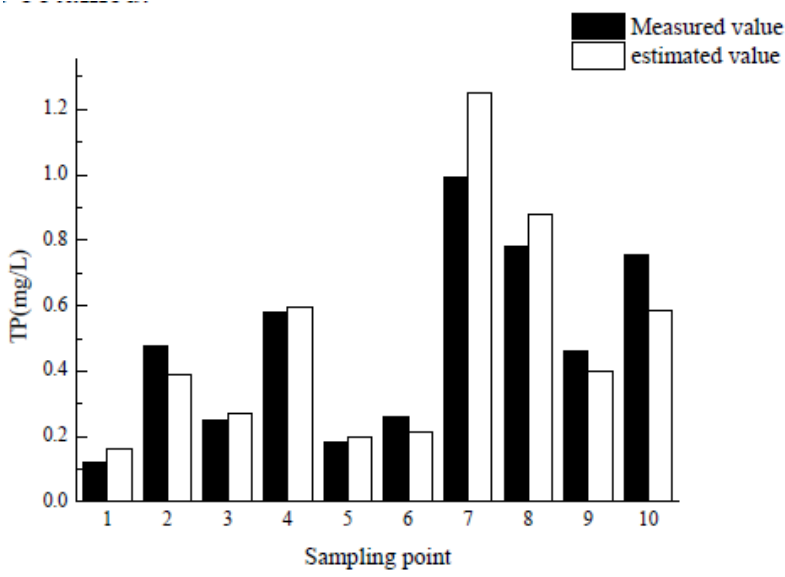

Fig. 2. Comparison of estimated and measured values of TP concentration

Table 3. Model accuracy analysis

\begin{tabular}{|c|c|c|c|}
\hline model & \multicolumn{2}{|c|}{$\begin{array}{c}\mathrm{C}_{\mathrm{TP}}=1.912-6.64 \times(\mathrm{B} 2-\mathrm{B} 5) \\
+14.135 \times(\mathrm{B} 2-\mathrm{B} 5)^{3}\end{array}$} & $\mathrm{R}^{2}=0.903$ \\
\hline $\begin{array}{c}\text { sampling } \\
\text { point }\end{array}$ & $\begin{array}{c}\text { measured } \\
\text { value }(\mathrm{mg} / \mathrm{L})\end{array}$ & $\begin{array}{c}\text { estimated } \\
\text { value }(\mathrm{mg} / \mathrm{L})\end{array}$ & $\begin{array}{c}\text { relative } \\
\text { error }\end{array}$ \\
\hline 1 & 0.1186 & 0.1626 & $37.1 \%$ \\
\hline 2 & 0.4750 & 0.3381 & $18.3 \%$ \\
\hline 3 & 0.2513 & 0.2682 & $6.74 \%$ \\
\hline 4 & 0.5816 & 0.5969 & $2.68 \%$ \\
\hline 5 & 0.1830 & 0.1992 & $8.84 \%$ \\
\hline 6 & 0.2610 & 0.2133 & $18.2 \%$ \\
\hline 7 & 0.9942 & 1.2528 & $26.0 \%$ \\
\hline 8 & 0.7831 & 0.8804 & $12.4 \%$ \\
\hline 9 & 0.4622 & 0.4002 & $13.3 \%$ \\
\hline 10 & 0.7530 & 0.5843 & $22.3 \%$ \\
\hline
\end{tabular}

Combined with Figure 2 and Table 3, the estimated value of most points differs from the measured value by about $20 \%$. Among the ten sampling points, the difference between the measured value of the sampling point and the estimated value is $37.1 \%$, and the difference between the measured values of the sampling points of 3, 4, and 5 is small, which are $6.74 \%, 2.68 \%$, and $8.84 \%$, respectively. It can be considered that the model predicts good results. It can be seen from Table 4 that the concentration of TP in most of the Ring River is above $0.1 \mathrm{mg} / \mathrm{L}$. On the one hand, because the Ring River is located in the center of Hefei City, there are many shopping malls nearby, and the flow of people is large. On the other hand, the water body of the Ring River is semi-closed. The supplementary water source is mainly natural rainfall and reclaimed water. The water body 
communication ability and regulation and repair ability are poor, and the water body is highly eutrophic.

Table 4. Surface water environmental quality standard project limit (TP) $\mathrm{mg} / \mathrm{L}$

\begin{tabular}{|c|c|c|c|c|c|}
\hline classification & $\begin{array}{c}\text { Class } \\
\text { I }\end{array}$ & $\begin{array}{c}\text { Class } \\
\text { II }\end{array}$ & $\begin{array}{c}\text { Class } \\
\text { III }\end{array}$ & $\begin{array}{c}\text { Class } \\
\text { IV }\end{array}$ & $\begin{array}{c}\text { Class } \\
\text { V }\end{array}$ \\
\hline Standard value & $\leq 0.02$ & $\leq 0.1$ & $\leq 0.2$ & $\leq 0.3$ & $\leq 0.4$ \\
\hline
\end{tabular}

At present, the laboratory determines that the TP concentration needs to be carried out within 24 hours of sampling, which has high requirements on the timeliness of the experiment, and it is very difficult to study in some departments where the laboratory and the research area are far away. Although transportation is very developed today, it will inevitably be affected by the weather and other factors that are difficult to coordinate, which will result in the water sample not being able to be accurately and timely measured in a short time. Therefore, remote sensing technology is currently used to monitor lake water quality because of its real-time and comprehensive The monitoring has been favored by many scholars at home and abroad. Due to the traffic congestion near the Ring River, the sampling time of 10 points generally takes half a day, and the accuracy of the measured measurement may be biased to some extent due to the time relationship. As shown in Table 3, the point where the error is greater than $30 \%$ occupies one, the point with the error less than $10 \%$ accounts for 3 , and the remaining error is about $20 \%$. Therefore, the improvement of the accuracy of the measured values is also one of the important conditions for establishing a high-precision model.

\subsection{Application of the model}

Applying the total phosphorus inversion model to the total phosphorus concentration in May-July 2019, May 31, 2019, June 16, 2019, July 2, 2019, and remote sensing images from May to July The distribution map, which is May 15, 2019, May 31, 2019, and June 16, 2019, has a large amount of cloud inversion, and the data is inversion on July 2, 2019. The inversion results are shown in Figure 3.

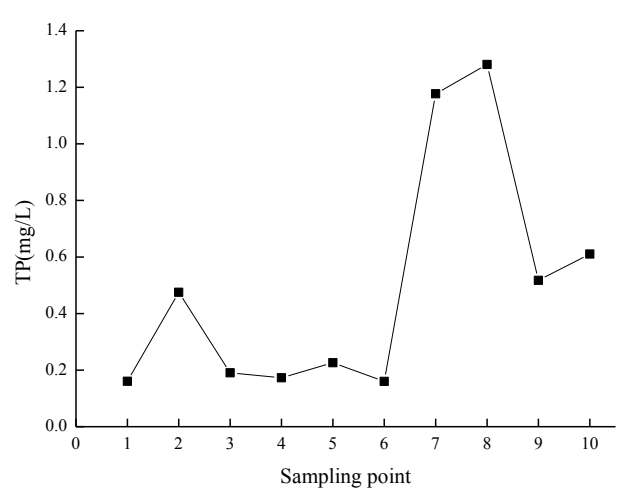

Fig. 3. Distribution of TP concentration in the Ring River on July 2, 2019
As can be seen from Figure 4, the total phosphorus concentration in the Ring River in July was mostly above $1 \mathrm{mg} / \mathrm{L}$. It is widely recognized with the internationally recognized critical concentration of eutrophication: TP is $0.02 \mathrm{mg} / \mathrm{L}$, indicating that the nitrogen and phosphorus source elements in the water can fully meet the needs of algae growth, once the temperature, light, hydrodynamic conditions, etc. are suitable. Algae may grow and multiply rapidly, leading to deterioration of water quality ${ }^{[12]}$. Compared with the detection of TP concentration in March and April, the TP concentration in July is on the rise. The reason is that it will enter the summer season, and the growth and reproduction of various animals and plants in the water body and the metabolism will accelerate, resulting in an increase in the concentration of phosphorus and a large fluctuation. This also indicates that with the imminent entry into the summer, the phosphorus content in the waters of the Ring River will likely be in unstable fluctuations, and monitoring should be increased. The water quality changes in the 3rd, 4th and 7 th months of the Ring River are shown in Figure 4.

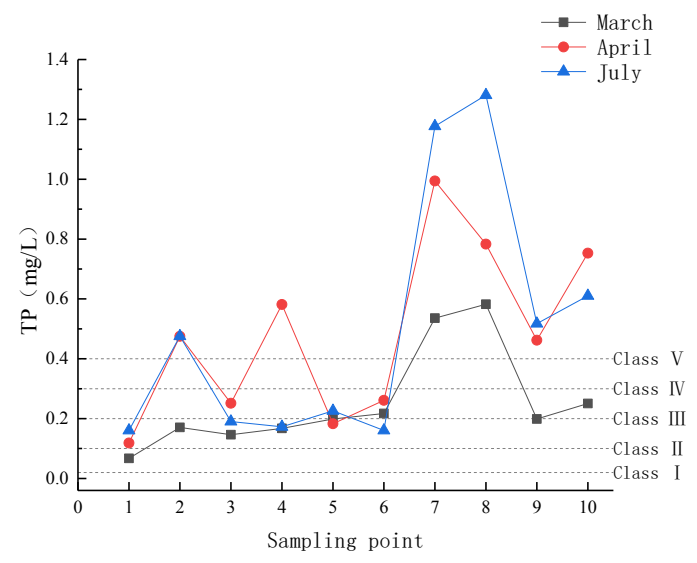

Fig. 4. TP concentration changes in the three months of the Ring River

\section{Conclusion}

In this paper, through the use of Landsat-8, combined with the measured water quality parameters, a remote sensing inversion of the total phosphorus concentration in the Ring River was carried out. Through experimental analysis, it is concluded that the B2-B5 band has the best correlation with total phosphorus, and the binary linear regression model is obtained. The model was applied to the satellite imagery in July, and the total phosphorus concentration in July was obtained. The water quality of the Ring River in the 3rd, 4th and 7th months was analyse based on the measured data. It is concluded that with the increase of temperature, the growth and reproduction of animals and plants in the water and the acceleration of metabolism, the total phosphorus concentration in the Ring River is on the rise, and the eutrophication is intensified. With the arrival of summer, the water quality monitoring of the Ring River should be increased to prevent the pollution of water bodies from increasing.

The accuracy of the model obtained in this survey is 
not very high, and further verification of its applicability is needed. The regression analysis model is a semiempirical model, but since the statistical model itself will also affect the accuracy and applicability of the model, the accuracy of the obtained model will be limited. Therefore, in the further study, multiple analysis methods should be used for comparative analysis and correction. To get a more accurate model. In addition, the sampling points of this experiment are relatively small, and the remote sensing data that are not in synchronization with the sampling time are used, which may affect the results to some extent. In this experiment, only the inversion of TP concentration was performed, and the water quality parameter inversion model could not be fully constructed. Therefore, in order to carry out all-round remote sensing monitoring of the water quality of the Ring River, in the future investigation and research, the number of sampling points can be increased in an appropriate amount, and time sampling detection simultaneously with the remote sensing data should be selected as much as possible. At the same time, the water quality parameters such as chlorophyll, total phosphorus and total nitrogen should be model and inverted.

\section{References}

1. Naselli-flores L. Urban Lakes: Ecosystems at Risk, Worthy of the Best Care [J]. PoT 2007: The 12th World Lake Conference, Jaipur, India, 1333-1337(2007).

2. W.b.Yang , G.x.Wang, L.m Zhang, et al. On Temporal-spatial Variability of Water Quality and Environmental Stress of Kuncheng Lake in Changshu City [J]. JONR, 22(2): 185-192(2007).

3. Y.f Xu, Y.m.Li, Q .Wang, et al. Eutrophication evaluation of three lakes and one reservoir using CCD images from the HJ-1 satellite [J]. JoES, 31(1): 81- 93, (2011).

4. C.c Zhang, X.n,D N Zhang, et al. Comparative
Study of the Remote Sensing Image Classification Method Based on Water Area Estimation [J]. MaE,31(3): 24-28(2008).

5. S.Jiang Remote Sensing Monitoring of Weihe River Water Quality Based on High Resolution Remote Sensing Image[D]. Shaanxi Normal University, (2009).

6. S.h.Chen Study on phytoplankton and water quality of main closed water bodies in downtown area of Hefei [D]. Anhui Jianzhu University (2017).

7. Alcantara E, Bernardo $\mathrm{N}$, Rodrigues $\mathrm{T}$, et al. Modeling the spatio-temporal dissolved organic carbon concentration in Barra Bonita reservoir using OLI/Landsat-8 images[J]. Modeling Earth Systems and Environment, 3(1):11(2017).

8. M.d.Yan, Study on water quality inversion model of Qinghe Reservoir based on Landsat-8 satellite image data [D]. Shenyang Agricultural University (2016).

9. Bernardo N, Watanabe F, Rodrigues $\mathrm{T}$, et al. Atmospheric correction issues for retrieving total suspended matter concentrations in inland waters using OLI/Landsat-8 image[J]. Advances in Space Research, 59(9), 2335-2348 (2017).

10. H.p Liu, Classification of greening tree species in Hohhot based on WorldView-II data [D]. Inner Mongolia Agricultural University (2013).

11. Zhu L.y, S.x.Wang, Y, Zhou et al. Determination of Chlorophyll-a Concentration in Taihu Lake Using MODIS Image Data [J]. RSI, 2006(2): 25-28 (2006).

12. K.f Liu. Characteristics and evaluation of water environment change of typical landscape water bodies in Hefei urban area [D]. Hefei University of Technology (2014). 